\title{
Salting-out induced liquid-liquid microextraction for alogliptin benzoate determination in human plasma by HPLC/UV
}

Sherin F. Hammad', Inas A. Abdallah², Alaa Bedair ${ }^{2}$ and Fotouh R. Mansour 1,3*

\begin{abstract}
Salting-out induced liquid-liquid microextraction method has been developed for plasma sample treatment before determination of alogliptin by high performance liquid chromatography with UV detection. Several parameters were optimized to achieve maximum enrichment, including type of extractant, volume of extractant, type of anion, type of cation, salt amount and pH. The optimum conditions were attained using $500 \mu \mathrm{L}$ of acetonitrile, added to $1 \mathrm{~mL}$ of aqueous sample containing $250 \mathrm{mg}$ of sodium chloride at $\mathrm{pH}$ 12. An RP-HPLC method was developed and validated according to the International Conference on Harmonization guidelines M10. The method was linear in the concentration range of 0.1 to $50 \mu \mathrm{g} / \mathrm{mL}$ (correlation coefficient $=0.997$ ). The limit of detection was $0.019 \mu \mathrm{g} / \mathrm{mL}$ and limit of quantitation was $0.06 \mu \mathrm{g} / \mathrm{mL}$. The method was accurate and precise with an average $\%$ recovery of $99.7 \%$ and a $\%$ relative standard deviation ranging between 1.5 and 2.5. These results showed that the salting-out induced liquid-liquid microextraction methods could be better than other sample preparation protocols in terms of sensitivity, easiness, solvent consumption and waste reduction.
\end{abstract}

Keywords: Alogliptin, Plasma, Salting-out, Microextraction, Sitagliptin

\section{Introduction}

Sample preparation is a critical step in method development and application. The goal of sample preparation is to purify and concentrate the target analyte before analysis. Generally, sample treatment helps to enhance separation and quantitation of target analytes and protects analytical instruments [1]. Protein precipitation is the simplest biological sample preparation technique, as it requires simple mixing of samples with miscible organic solvents or mineral acids followed by centrifugation. However, the dilution effect of protein precipitation procedures compromises method sensitivity. Liquid-liquid extraction (LLE) is a better option for sample preparation

\footnotetext{
*Correspondence: fotouhrashed@pharm.tanta.edu.eg

${ }^{1}$ Department of Pharmaceutical Analytical Chemistry, Faculty

of Pharmacy, Tanta University, Elgeish Street, The Medical Campus of

Tanta University, Tanta 31111, Egypt

Full list of author information is available at the end of the article
}

that includes using large volumes of water immiscible organic solvents (e.g. Chloroform, ether, ethyl acetate), followed by evaporation and reconstitution in the least possible amount of a suitable solvent. These procedures render LLE labor-intensive, time-consuming and nonecofriendly [2-4]. Moreover, LLE is limited to extraction of hydrophobic analytes due to the use of water immiscible hydrophobic extractants $[5,6]$.

Water-miscible polar organic solvents can be used for sample preparation in a mode known as salting-out induced liquid-liquid extraction (SALLE). In SALLE, solvents such as acetonitrile, isopropanol and acetone are mixed with the aqueous sample before phase separation is induced by adding enough amount of a suitable salt [7]. SALLE is an efficient technique for extraction of hydrophilic analytes $[8,9]$ and the employment of water miscible organic solvents make SALLE compatible with most analytical methods. SALLE has already been used for extraction of drugs from different matrices, 
including plasma [10-13] whole blood [14], serum[15], urine [16], fruit juice [17], milk [18] and water [19, 20].

Miniaturization of sample preparation techniques is a recent trend in analytical chemistry. Decreasing solvent consumption decreases the cost of analysis, reduces organic wastes, protect operator's health and preserve the environment. Miniaturized liquid-liquid extraction (also known as liquid-liquid microextraction, LLME) differs from conventional LLE in two aspects [21, 22]: the need for microliters of organic solvents rather than milliliters, and the tendency to extract small but representative amounts of the analyte in the aqueous sample. This small extracted amount of the drug will be highly concentrated in the minute volume of organic extractant, which makes LLME highly efficient in sample pre-concentration.

In this work, we present salting-out induced liquidliquid microextraction (SALLME) for preparation and analysis of alogliptin in human plasma by HPLC/ UV, using sitagliptin as an internal standard (IS). Figure 1 shows the chemical structures of the drug and the internal standard. Alogliptin is an oral drug for Type 2 diabetes mellitus that works by inhibiting dipeptidyl peptidase 4 (DPP-4). The reported $\mathrm{C}_{\max }$ of alogliptin was $0.11 \mu \mathrm{g} / \mathrm{mL}$ at a dose of $25 \mathrm{mg}$ [23]. Due to the low $\mathrm{C}_{\max }$, determination of alogliptin in plasma necessitated using highly sensitive techniques such as LCMS/MS after protein precipitation of samples [23-26]. However, protein precipitation induces ionization suppression in MS detection $[27,28]$ and precludes detection by other less sensitive detectors such as UV. Using SALLME in sample preparation enabled enrichment and determination of alogliptin in plasma using HPLC/ UV with acceptable accuracy, precision and sensitivity.

\section{Experimental}

\section{Chemicals and reagents}

Alogliptin benzoate (99.7\%) and sitagliptin phosphate monohydrate $(99.8 \%)$ were kindly supplied from Global Nabi Pharmaceuticals (6th of October City, Egypt). Acetonitrile, potassium dihydrogen phosphate, phosphoric acid, methanol and sodium hydroxide were purchased from Merck (Darmstadt, Germany). Sodium carbonate and sodium sulfate were purchased from Pharaohs Chem (Obour City, Egypt). Sodium chloride and propylene glycol were purchased from El-Gomhouria Company (Cairo, Egypt). Sodium acetate, sodium thiosulfate and sodium dihydrogen phosphate were purchased from Alpha Chemicals (Cairo, Egypt). Glycerol was purchased from Sigma Aldrich (St. Louis, MO, USA). Tetrahydrofuran was purchased from Universal Fine Chemicals (Sanborn, NY, USA) while calcium chloride and potassium chloride were purchased from Piochem (6th of October, Egypt). Magnesium chloride was purchased from Chem Lab (Zedelgem, Belgium). Human plasma samples were kindly provided by Vacsera National Blood Bank, (Giza, Egypt)

\section{Instrumentation}

The determination of alogliptin was done on a Dionex UltiMate 3000 HPLC (Thermo Scientific ${ }^{\mathrm{TM}}$, Dionex ${ }^{\mathrm{TM}}$, Sunnyvale, CA, USA). The instrument composed of a WPS-3000TSL autosampler, an LPG-3400SD quaternary pump, a VWD-3000 variable wavelength detector and a TCC-3000SD column thermostat. Data processing and acquisition were carried out by Chromeleon 7 software. Tabletop Cyan-CL008 centrifuge (Hulshout,Belgium) was used. The $\mathrm{pH}$ values were adjusted by Jenway 3510 pH-meter (Staffordshire,UK).

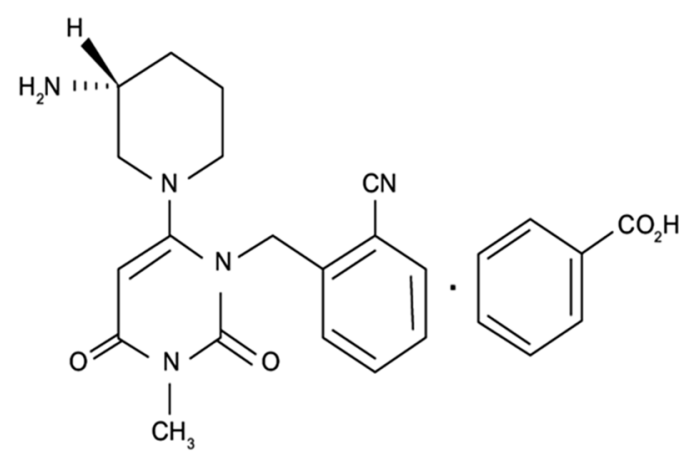

Alogliptin benzoate

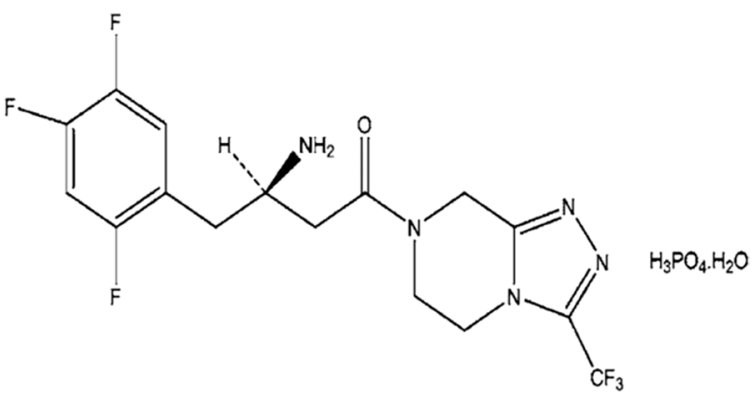

Sitagliptin phosphate monohydrate

Fig. 1 The chemical structure of the analyte (alogliptin benzoate) and the internal standard (sitagliptin phosphate monohydrate) 


\section{Chromatographic conditions}

The chromatographic conditions were run in an isocratic elution mode, using a mobile phase consisting of $50 \mathrm{mM}$ phosphate buffer $(\mathrm{pH}=2.5)$ and acetonitrile in a ratio of $70: 30, v / v$. The volume of injection was $5 \mu \mathrm{L}$, the flow rate was $1 \mathrm{~mL} / \mathrm{min}$, the wavelength of detection was $210 \mathrm{~nm}$ and the column temperature was set at $30{ }^{\circ} \mathrm{C}$ (303K) .Chromatographic separation was done on a Thermo Hypersil ODS C18 column $(150 \mathrm{~mm} \times 4.6 \mathrm{~mm}$, $5 \mu \mathrm{m})$.

\section{Stock and working solutions}

Stock solutions of alogliptin benzoate and sitagliptin phosphate monohydrate $(1 \mathrm{mg} / \mathrm{mL}$ for each) were separately prepared in distilled water, and stored at $4{ }^{\circ} \mathrm{C}$ $(277 \mathrm{~K})$. To study different conditions on extraction performance, water samples were obtained by spiking distilled water with alogliptin at a concentration of $25 \mu \mathrm{g} /$ $\mathrm{mL}$.

\section{Extraction procedure}

The procedures of SALLME were optimized as follows: salt amount (Sodium chloride) $(250 \mathrm{mg}$ ) was added to $5 \mathrm{~mL}$ screw cap glass test tube containing $1 \mathrm{~mL}$ of aqueous sample solution then the tube was vortexed for $2 \mathrm{~min}$. A volume of $500 \mu \mathrm{L}$ of acetonitrile was added to the previous solution, then the tube was vortexed again for $2 \mathrm{~min}$ followed by centrifugation for $5 \mathrm{~min}$ at $4000 \mathrm{rpm}$. The upper layer was pipetted $(20 \mu \mathrm{L})$ and was transferred into an HPLC vial for analysis. Figure 2 summarizes the applied SALLME procedures for alogliptin.

\section{Method performance evaluation}

The validation of SALLME was performed by spiking of plasma with alogliptin benzoate and using sitagliptin phosphate monohydrate as internal standard. The therapeutic level of alogliptin was used as a reference in selecting the linearity range [23]. The calibration curve was constructed by plotting the analyte-to-IS peak area ratio $(y)$ versus the analyte nominal concentration $(x)$. The method sensitivity was determined by the limit of detection (LOD) and limit of quantitation (LOQ). The linearity of the method was assessed by calculating the correlation coefficient. Intra-day $(n=3)$ and inter-day $(n=3)$ accuracy and precision determined by $\%$ recovery and relative standard deviation (Table 2).

\section{Freeze and thaw stability study}

The freeze and thaw stability of alogliptin was investigated in human plasma at three concentration levels: 5, 20, $40 \mu \mathrm{g} / \mathrm{mL}$. The plasma samples were spiked with the quality control concentrations and frozen at $-20{ }^{\circ} \mathrm{C}$ $(253 \mathrm{~K})$, and the samples were later thawed at room temperature till complete thawing, then analyzed. This process of freeze and thaw was repeated for three cycles, and the alogliptin concentration was measured after each cycle and compared with the zero cycle concentration. The samples were considered stable if the \% recovery

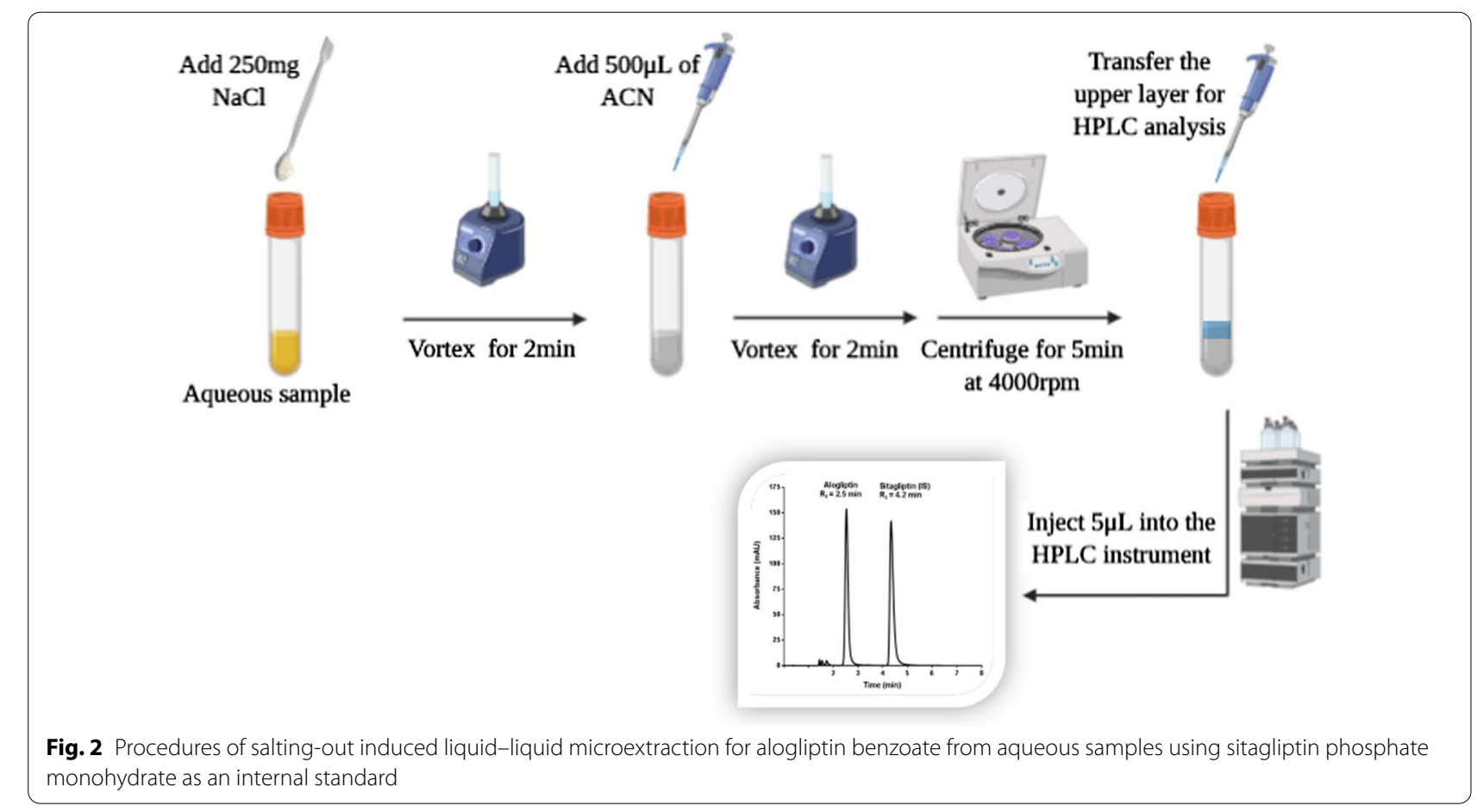


were within $15 \%$ of the nominal concentrations and \% relative standard deviation (RSD) were less than 15\% [29].

\section{Application to biological samples}

Human blood Plasma $(400 \mu \mathrm{L})$ was spiked with different concentrations of alogliptin and the internal standard $(25 \mu \mathrm{g} / \mathrm{mL})$ to attain the desired therapeutic levels of the drug and to construct the calibration curve. Then, $500 \mu \mathrm{L}$ of acetonitrile was added to plasma, vortexed for $2 \mathrm{~min}$, then the tube was centrifuged for $5 \mathrm{~min}$ at $4000 \mathrm{rpm}$. The upper layer was transferred to another test tube followed by the addition of $10 \mu \mathrm{L}$ of $1 \mathrm{M} \mathrm{NaOH}$ to adjust the $\mathrm{pH}$ value at 12 . Then $490 \mu \mathrm{L}$ of distilled water and $250 \mathrm{mg}$ sodium chloride were added and the tube was vortexed for $2 \mathrm{~min}$ followed by centrifugation for $5 \mathrm{~min}$ at $4000 \mathrm{rpm}$. The upper layer was pipetted and transferred to HPLC vial for analysis.

\section{Statistical analysis}

The optimization parameters were studied using three replicates and the data were presented as the average \pm standard deviation $(\mathrm{n}=3)$. Statistical analysis was performed using the SPSS statistical package (V. 24) to compare the mean and the variance of the developed method with the reference method using Student t-test and F-test. The results of the comparison study were expressed as average \pm standard deviation $(\mathrm{n}=3)$, and the p-values were calculated for both tests at the $95 \%$ confidence level $(\alpha=0.05)$.

\section{Result and discussion}

In this work, SALLME was tried for alogliptin extraction from plasma. Different factors were studied to achieve the maximum enrichment. Different solvents, volumes of extractant, anions, cations, amounts of salt and $\mathrm{pH}$ values were investigated. Optimization of these parameters was performed using one-factor-at-a-time (OFAT). The peak area was the parameter to evaluate the effect of each factor on extraction.

\section{Organic solvent optimization}

Preliminary experiments were done to investigate the optimum extractant using different solvents including methanol, propylene glycol, glycerol, tetrahydrofuran and acetonitrile. A $2000 \mu \mathrm{L}$ of each solvent was added to $1 \mathrm{~mL}$ of aqueous solution containing $250 \mathrm{mg}$ of sodium chloride followed by vortexing for $2 \mathrm{~min}$, then the tube was centrifuged for $5 \mathrm{~min}$ at $4000 \mathrm{rpm}$. The results showed that there is no phase separation with methanol, propylene glycol, and glycerol, which could be due to the high polarity of the hydroxyl groups and the multiple $\mathrm{H}$-bonds formed between these solvents and water. On the other hand, both tetrahydrofuran and acetonitrile could induce phase separation, but the background noise in tetrahydrofuran after injection into HPLC/UV was significantly higher than acetonitrile. For this reason, acetonitrile was chosen as the optimum extractant in the following SALLME procedures.

\section{Acetonitrile volume optimization}

The extractant volume is the most important factor that could affect the sample enrichment in SALLME. Generally, analyte pre-concentration is inversely proportional to the volume of extractant [30]. Different volumes of acetonitrile were investigated in the range of 100 to $2000 \mu \mathrm{L}$. The results showed that $450 \mu \mathrm{L}$ was the least volume of acetonitrile that could be used in SALLME. Using volumes of acetonitrile lower than $450 \mu \mathrm{L}$ could not induce phase separation. As shown in Fig. 3, the highest response was observed using $500 \mu \mathrm{L}$ acetonitrile, thus it was designated as the optimum acetonitrile volume in the following procedures.

\section{Anion- type optimization}

Different anions were investigated to select the optimum anion that could achieve the best extraction efficiency. All anions were sodium salts of monovalent (Chloride and acetate), divalent (Sulfate, thiosulfate, carbonate) and trivalent (Phosphate) anions. Figure 4 shows that the highest extraction efficiency was achieved with chloride. The mechanism of salting-out depends on hydrophobic effect and electrostatic repulsion [31]. In this aspect, ions with high charge density (charge/size) are expected to interact strongly with water and induce more electrostatic repulsion [32]. The small size of chloride compared with other anions may explain the observed high efficiency. It is

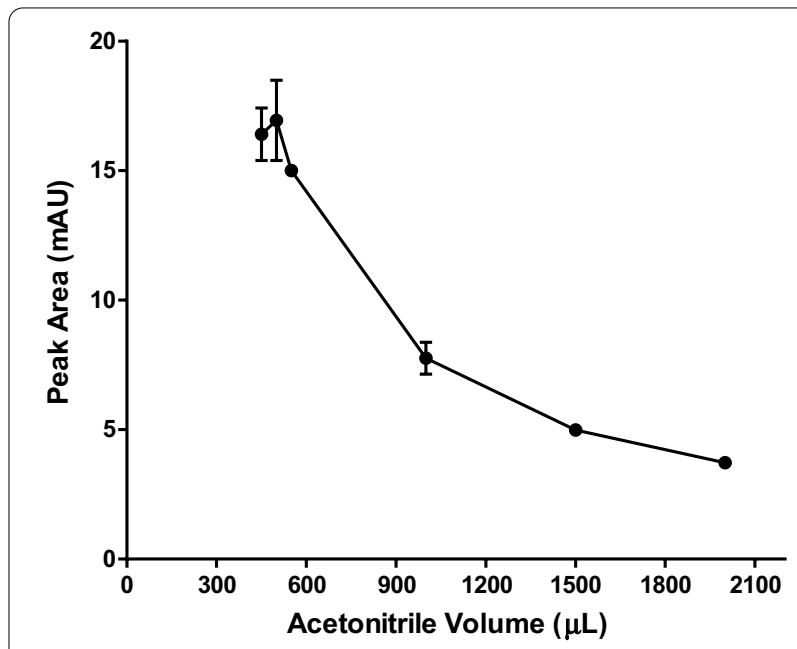

Fig. 3 Effect of acetonitrile volume $(\mu \mathrm{L})$ on the efficiency of SALLME of alogliptin benzoate 


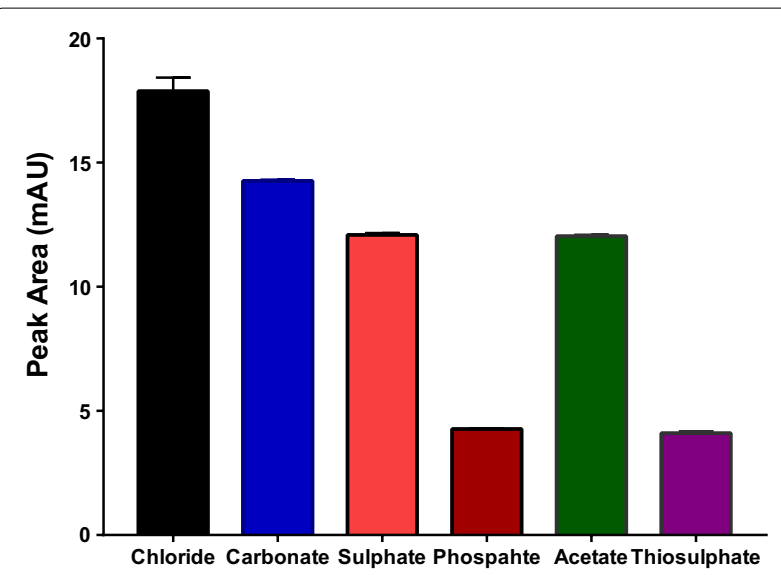

Fig. 4 Effect of extractant type on the efficiency of SALLME of alogliptin benzoate

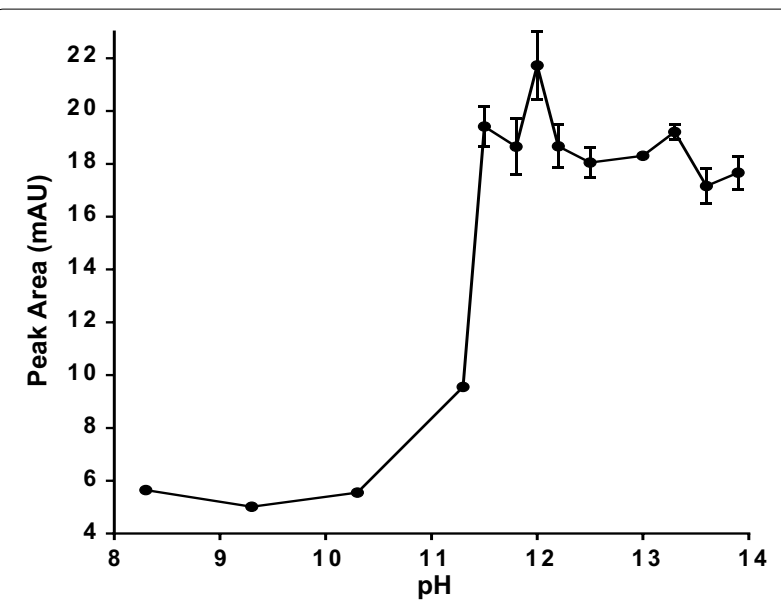

Fig. 5 Effect of diluent pH on the efficiency of SALLME of alogliptin benzoate here worth mentioning that the volume retrieved of acetonitrile after adding chloride was small compared with other anions which helped make the analyte more concentrated in the separated layer of acetonitrile. Further optimization was performed by using a binary mixture of chloride/carbonate, the two anions that could attain the best results, but in different ratios. Adding carbonate to chloride resulted in higher phase ratios (Retrieved volume of ACN/Aqueous volume). However, using chloride alone was better than its mixtures with carbonate. Thus, chloride was selected as the optimum anion in this step.

\section{Cation-type optimization}

The type of salt cation has a role in salting-out phenomena, but to less extent than the anion component. Seven cations were tested, all in chloride salts including monovalent (Soidum and potassium), divalent (Copper, cobalt, calcium and magnesium) and trivalent (Ferric) cations. Transition metals (Copper, cobalt and ferric) were found not suitable due to the observed color, which could complicate the sample matrix. No phase separation was observed in case of potassium and magnesium, while sodium and calcium could successfully induce salting out of the acetonitrile layer. Compared with calcium, sodium could achieve higher extraction efficiency due to the small size of sodium, which could enhance charge density and salting out capabilities [31]. Therefore, sodium chloride was selected as an optimum salt for SALLME of alogliptin from plasma, because it was cheap, safe, available and more efficient.

\section{pH Optimization}

In extraction methods, $\mathrm{pH}$ plays a major role due to its effect on solubility and ionization of drugs. Different $\mathrm{pH}$ values were investigated in the range of 8.3 to
13.9, adjusted using the appropriate concentration of sodium hydroxide to span the pKa value of alogliptin $(\mathrm{pKa}=9.47)$. Figure 5 shows low peak areas for alogliptin at $\mathrm{pH}$ values lower than 9.47 due to the predominance of the ionized form. Further increases in $\mathrm{pH}$ were associated with a corresponding pronounced increase in response up to $\mathrm{pH} 11.5$. Increasing $\mathrm{pH}$ above 11.5 did not significantly affect the obtained response. The highest extraction efficiency was achieved with $\mathrm{pH}=12$ followed by a steady state in the range of 13 to 13.9 . At $\mathrm{pH}=12$, alogliptin will be in the non-ionized form, leading to better extraction efficiency. Therefore, the selected optimum $\mathrm{pH}$ value was 12 .

\section{Chloride amount optimization}

To study the effect of salt amount on SALLME performance, different amounts of sodium chloride were tried in the range of $100 \mathrm{mg}$ to $600 \mathrm{mg}$. The results showed that the salt amount had a small effect on extraction efficiency. The peak areas of alogliptin benzoate were comparable regardless of the amount of sodium chloride. As shown in Fig. 6, $250 \mathrm{mg}$ of $\mathrm{NaCl}$ resulted in slightly higher responses, thus it was selected as the optimum amount in the following procedures.

\section{Method validation}

The chromatographic method was validated according to the International Conference of Harmonization ( $\mathrm{ICH}$ ) guidelines M10 [29]. The following parameters were investigated: linearity, precision, accuracy, limit of detection (LOD) and limit of quantitation (LOQ). The method was found linear in the range of 0.1 to $50 \mu \mathrm{g} / \mathrm{mL} \mathrm{Accu-}$ racy and precision were determined by $\%$ recovery and $\%$ 


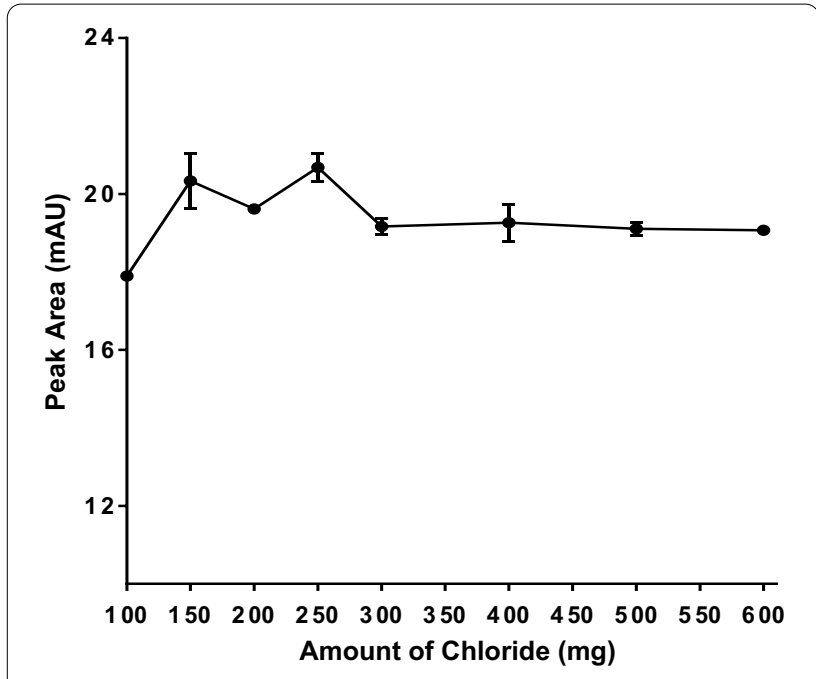

Fig. 6 Effect of chloride amount (in $\mathrm{mg}$ ) on the efficiency of SALLME of alogliptin benzoate

RSD, respectively. The results were satisfactory for bioanalysis application.

\section{Linearity}

The method linearity was investigated in the concentration range of 0.1 to $50 \mu \mathrm{g} / \mathrm{mL}$. The calibration curve was constructed by plotting the response ratio (ratio between peak area of alogliptin and peak area of sitagliptin) on the $y$-axis and alogliptin concentration on the $x$-axis (in $\mu \mathrm{g} / \mathrm{mL}$ ). The calibration curve indicated a linear relationship between response ratio and alogliptin concentration with an acceptable correlation coefficient and regression parameters as summarized in Table 1.

\section{Accuracy and precision}

Method accuracy was investigated by analyzing plasma samples, spiked with alogliptin at three concentrations: 5,20 and $40 \mu \mathrm{g} / \mathrm{mL}$, each prepared in triplicate. Table 2 indicates that the \% recovery was in the range of 98 to 101 , with an average \%recovery of 99.76 . The precision of the analytical method was investigated by analyzing plasma samples, spiked with alogliptin at the same three concentrations, each prepared in triplicate. The concentrations were analyzed in the same day to test repeatability and in 3 consecutive days to evaluate intermediate precision. Based on the \%RSD shown in Table 2, the method intraday and interday precision were acceptable for bioanalysis application.

\section{Limit of detection and Limit of quantitation}

Limit of detection (LOD) and limit of quantitation (LOQ) were calculated according to the following equations:

$$
\begin{aligned}
& L O D=\frac{3.3 \times \text { S.D of Blank }}{\text { Calibration curve slope }} \\
& L O Q=\frac{10 \times \text { S.D of Blank }}{\text { Calibration curveslope }}
\end{aligned}
$$

where SD is the standard deviation of 10 blank injections. LOD was $0.019 \mu \mathrm{g} / \mathrm{mL}$ and LOQ was $0.06 \mu \mathrm{g} / \mathrm{mL}$.

Table 1 Quantitative analysis and regression line

\begin{tabular}{lllllll}
\hline Compound & Slope & Intercept & r & Range & LOD & LOQ \\
\hline Alogliptin & 0.0272 & 0.0012 & 0.997 & $0.1-50 \mu \mathrm{g} / \mathrm{mL}$ & $0.019 \mu \mathrm{g} / \mathrm{mL}$ & $0.06 \mu \mathrm{g} / \mathrm{mL}$ \\
\hline
\end{tabular}

$R^{2}$ Regression coefficient, LOD Limit of detection, LOQ Limit of quantitation

\begin{tabular}{|c|c|c|c|c|c|c|}
\hline \multirow[t]{3}{*}{ Parameter } & \multicolumn{6}{|c|}{ Accuracy \& precision } \\
\hline & \multicolumn{3}{|l|}{ Intraday } & \multicolumn{3}{|l|}{ Interday } \\
\hline & Added $(\mu \mathrm{g} / \mathrm{mL})$ & Found $(\mu \mathrm{g} / \mathrm{mL})$ & Found (\%) & Added ( $\mu \mathrm{g} / \mathrm{mL})$ & Found ( $\mu \mathrm{g} / \mathrm{mL})$ & Found (\%) \\
\hline \multirow[t]{3}{*}{ Alogliptin } & 5 & 5.05 & 101.00 & 5 & 5.02 & 100.44 \\
\hline & 20 & 19.97 & 99.85 & 20 & 19.99 & 99.93 \\
\hline & 40 & 39.38 & 98.43 & 40 & 39.60 & 99.01 \\
\hline Mean & & & 99.76 & & & 99.79 \\
\hline$\%$ RSD & & & 1.56 & & & 2.57 \\
\hline
\end{tabular}

Table 2 Intra-day and inter-day precision and accuracy

$R S D$ relative standard deviation 
SALLME was found sensitive for determination alogliptin in biological samples obtained from alogliptin clinical study.

\section{Freeze and thaw stability study}

The freeze and thaw stability study was performed by spiking human plasma with alogliptin at three quality control concentration levels $(5,20$ and $40 \mu \mathrm{g} / \mathrm{mL})$. The plasma samples were frozen for 12 hours, thawed for three cycles, and the concentration of alogliptin was determined after each cycle to be compared with the zero cycle. Table 3 indicates that alogliptin was stable for three freeze/thaw cycles.

\section{Comparison with other reported methods}

Due to the low plasma concentrations of alogliptin, most analytical methods used LC-MS/MS for quantitation after sample preparation using protein precipitation. While protein precipitation is a simple and fast method for sample treatment, its efficiency to remove interference and protect analytical instruments is less than perfect. Moreover, the dilution effect of the added precipitating agent compromises method sensitivity, which could be compensated by the inherent high sensitivity of mass detection. For sake of comparison, the developed SALLME method was compared with the reported protein precipitation procedure [27] under the same chromatographic conditions. As shown in Fig. 7, a huge plasma peak appeared in the beginning of the chromatogram (retention time $=1.55 \mathrm{~min}$ )

Table 3 Freeze and thaw stability study

\begin{tabular}{|c|c|c|c|c|c|}
\hline & Added $(\mu \mathrm{g} / \mathrm{mL})$ & Found $(\mu \mathrm{g} / \mathrm{mL})$ & Recovery (\%) & RSD (\%) & RE (\%) \\
\hline \multirow[t]{3}{*}{ 1st cycle } & 5.00 & 4.98 & 99.63 & 4.28 & 0.37 \\
\hline & 20.00 & 19.98 & 99.91 & 3.39 & 0.09 \\
\hline & 40.00 & 41.03 & 102.58 & 3.26 & 2.58 \\
\hline \multirow[t]{3}{*}{ 2nd cycle } & 5.00 & 5.21 & 104.23 & 1.94 & 4.23 \\
\hline & 20.00 & 19.88 & 99.38 & 1.54 & 0.62 \\
\hline & 40.00 & 39.34 & 98.36 & 1.49 & 1.64 \\
\hline \multirow[t]{3}{*}{ 3rd cycle } & 5.00 & 5.09 & 101.73 & 3.66 & 1.73 \\
\hline & 20.00 & 20.57 & 102.83 & 0.98 & 2.83 \\
\hline & 40.00 & 38.89 & 97.23 & 4.92 & 2.77 \\
\hline
\end{tabular}
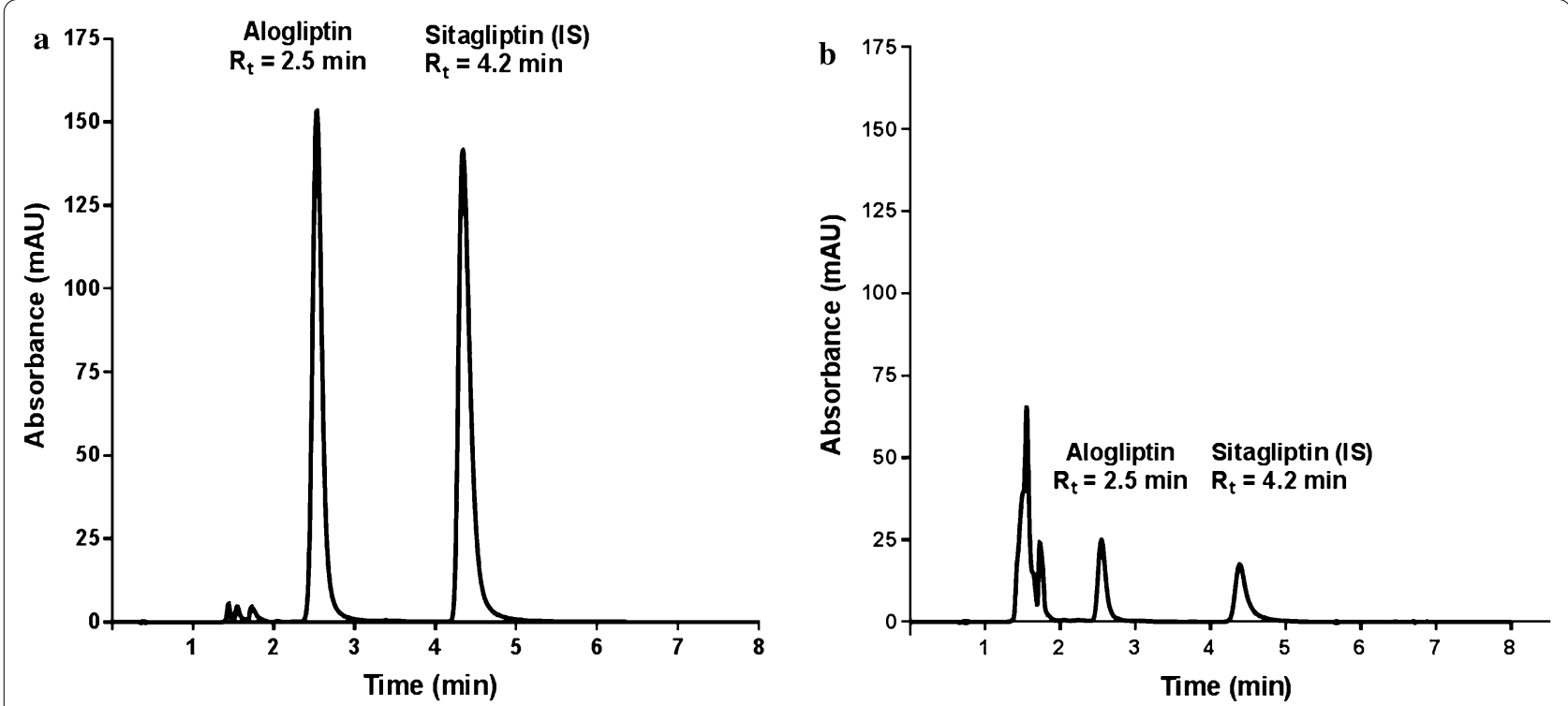

Fig. 7 Chromatographic separation of alogliptin benzoate and sitagliptin phosphate monohydrate using the proposed SALLME method (a) and the reported protein precipitation method $(\mathbf{b})$ 
Table 4 Comparison between the developed SALLME method and the reference LLE method [33]

\begin{tabular}{|c|c|c|c|c|c|c|}
\hline \multirow[t]{3}{*}{ Parameter } & \multicolumn{6}{|c|}{ Comparison with reference method } \\
\hline & \multicolumn{3}{|c|}{ The SALLME method } & \multicolumn{3}{|c|}{ Reference method } \\
\hline & $\begin{array}{l}\text { Added } \\
(\mu \mathrm{g} / \mathrm{mL})\end{array}$ & $\begin{array}{l}\text { Found* } \\
(\mu \mathrm{g} / \mathrm{mL})\end{array}$ & $\begin{array}{l}\text { Found } \\
(\%)\end{array}$ & $\begin{array}{l}\text { Added } \\
(\mu \mathrm{g} / \mathrm{mL})\end{array}$ & $\begin{array}{l}\text { Found } \\
(\mu \mathrm{g} / \mathrm{mL})\end{array}$ & $\begin{array}{l}\text { Found } \\
(\%)\end{array}$ \\
\hline & 5.00 & 4.96 & 99.15 & 5.00 & 4.96 & 99.29 \\
\hline & 10.00 & 10.08 & 100.75 & 10.00 & 10.23 & 102.26 \\
\hline & 20.00 & 20.02 & 100.08 & 20.00 & 20.20 & 101.01 \\
\hline Mean & & & 99.99 & & & 100.85 \\
\hline$\%$ RSD & & & 0.81 & & & 1.48 \\
\hline t-test $t^{* *}$ & & & 0.429 & & & \\
\hline F-test ${ }^{* *}$ & & & 0.450 & & & \\
\hline
\end{tabular}

* Average of five determinations for each concentration

** $p$-values at $95 \%$ confidence level $(a=0.05)$

compared with a very small peak at the same retention time in SALLME. This could be due to the dual function of acetonitrile to precipitate protein and to extract the drug after salting out. Moreover, the peak area of alogliptin treated with SALLME was more than seven times higher than that in the protein precipitation method. These results were achieved while only one third of the acetonitrile volume was consumed in the SALLME method which decreases organic solvent consumption, reduces organic waste, protects the operator and the environment and bestows green characteristics on the developed method.

Besides protein precipitation, conventional LLE [33] was also used for alogliptin determination in plasma by UPLC/DAD using diethyl ether as an extractant and a mobile phase consisting of acetonitrile:phosphate buffer $(50: 50, v / v)$ for reconstitution after evaporation. The results of the developed SALLME method were compared with the results of the reported LLE method using Student t-test and F-test at 95\% confidence level $(\alpha=0.05)$ as Table 4 shows. The statistical analysis indicated that there were no significant differences between the two methods. Although these results showed comparable accuracy and precision, the procedures in LLE were time consuming, non-ecofriendly, more expensive and required vacuum for solvent evaporation. On the other side, SALLME was simpler, cheaper, eco-friendlier and could achieve lower LOQ than the reported LLE method.

\section{Conclusions}

A SALLME method was developed for preparation of plasma samples for HPLC analysis. The method provided a simple, economical, fast and green approach for alogliptin extraction from biological samples. Moreover, acetonitrile, the employed extractant is compatible with different analytical instruments and HPLC detectors. The ability of this sample treatment to preconcentrate the sample makes possible UV detection after chromatographic separation under isocratic conditions. SALLME can be applied to other pharmaceutical compounds, especially highly polar drugs that are difficult to extract using conventional extracting solvents such as chloroform, methylene chloride, ethyl acetate and ether. Future work includes applying SALLME as a preparation method for other drugs using other analytical techniques such as UV/Vis spectroscopy, spectrofluorometry and capillary electrophoresis. Applying similar procedures for extraction of macromolecules is also in our scope. SALLME paves the way for simpler and greener extraction methods using the least possible amount of organic solvents. The small volumes and the safety of the organic solvents employed in SALLME makes it appreciably greener compared with the high volumes and the health hazardousness of other solvents used in conventional extraction.

\section{Abbreviations}

DAD: Diode-array detector; DPP-4: Dipeptidyl peptidase 4; ICH: International Conference of Harmonization; IS: Internal standard; LLE: Liquid-liquid extraction; LLME: Liquid-liquid microextraction; LOD: Limit of detection; LOQ: Limit of quantitation; OFAT: One-factor-at-a-time; RE: Relative error; RSD: Relative standard deviation; SALLE: Salting-out induced liquid-liquid extraction;

SALLME: Salting-out induced liquid-liquid microextraction.

\section{Authors' contributions}

SFH participated in the study design and the results discussion and revised the manuscript. IA participated in the study design and the results discussion and revised the manuscript. $A B$ conducted the practical work, participated in the results discussion and the preparation and writing of the manuscript. FRM proposed the study design, participated in the results discussion, manuscript preparation and revision. All authors read and approved the final manuscript. 


\section{Availability of data and materials}

The datasets used during the current study are available from the corresponding author on reasonable request.

\section{Ethics approval and consent to participate}

The experiment was conducted according to the rules of the Ethical committee of the Tanta University, Egypt.

\section{Consent for publication}

All the authors gave their consent for the publication of this article.

\section{Competing interests}

The authors declare that they have no competing interests.

\section{Author details}

${ }^{1}$ Department of Pharmaceutical Analytical Chemistry, Faculty of Pharmacy, Tanta University, Elgeish Street, The Medical Campus of Tanta University, Tanta 31111, Egypt. ${ }^{2}$ Department of Analytical Chemistry, Faculty of Pharmacy, University of Sadat City, 32958 Sadat City, Egypt. ${ }^{3}$ Pharmaceutical Services Center, Faculty of Pharmacy, Tanta University, Elgeish Street, The Medical Campus of Tanta University, Tanta 31111, Egypt.

Received: 27 August 2020 Accepted: 10 December 2020

Published online: 15 January 2021

\section{References}

1. Chen Y, Guo Z, Wang X, Qiu C (2008) Sample preparation. J Chromatogr A 1184(1-2):191-219. doi:https://doi.org/10.1016/j.chroma.2007.10.026

2. Sereshti H, Khosraviani M, Sadegh Amini-Fazl M (2014) Miniaturized salting-out liquid-liquid extraction in a coupled-syringe system combined with HPLC-UV for extraction and determination of sulfanilamide. Talanta 121:199-204. doi:https://doi.org/10.1016/j.talanta.2014.01.005

3. Heydari R, Lotfi Z, Ramezani M (2018) Simultaneous determination of zidovudine and lamivudine in plasma samples using miniaturized homogenous liquid-liquid extraction and high-performance liquid chromatography. J Anal Chem 73(11):1105-1110. https://doi.org/10.1134/ S1061934818110102

4. Moreno-González D, Rodríguez-Ramírez R, del Olmo-Iruela M, GarcíaCampaña AM (2017) Validation of a new method based on salting-out assisted liquid-liquid extraction and UHPLC-MS/MS for the determination of betalactam antibiotics in infant dairy products. Talanta 167(12):493498. doi:https://doi.org/10.1016/j.talanta.2017.02.045

5. Mansour FR, Danielson ND (2012) Separation methods for captopril in pharmaceuticals and biological fluids. J Sep Sci 35(10-11):1213-1226. doi:https://doi.org/10.1002/jssc.201200057

6. Mansour FR, Wei W, Danielson ND (2013) Separation of carnitine and acylcarnitines in biological samples: a review. Biomed Chromatogr 27(10):1339-1353. doi:https://doi.org/10.1002/bmc.2995

7. Gezahegn T, Tegegne B, Zewge F, Chandravanshi BS (2019) Salting-out assisted liquid-liquid extraction for the determination of ciprofloxacin residues in water samples by high performance liquid chromatographydiode array detector. BMC Chem 13(1):1-10. https://doi.org/10.1186/ s13065-019-0543-5

8. Heydarzadeh M, Givianrad MH, Heydari R, Aberoomand Azar P (2019) Salt-assisted liquid-liquid extraction in microchannel. J Sep Sci 42(20):3217-3224. doi:https://doi.org/10.1002/jssc.201900512

9. Myasein F, Kim E, Zhang J et al (2009) Rapid, simultaneous determination of lopinavir and ritonavir in human plasma by stacking protein precipitations and salting-out assisted liquid / liquid extraction, and ultrafast LC-MS/MS. Anal Chim Acta 651:112-116. doi:https://doi.org/10.1016/j. aca.2009.08.010

10. Rustum AM (1991) Assay of ibuprofen in human plasma by rapid and sensitive reversed-phase high-performance liquid chromatography application to a single dose pharmacokinetic study. J Chromatogr Sci 29(1):16-20. doi:https://doi.org/10.1093/chromsci/29.1.16

11. Tandel D, Shah P, Patel K, Thakkar V (2016) Salting-out assisted liquid-liquid extraction for Quanti fi cation of febuxostat in plasma using RP-HPLC and its pharmacokinetic application. J Chromatogr Sci 54(10):1827-1833. https://doi.org/10.1093/chromsci/bmw124

12. Zhang J, Rodila R, Gage E et al (2010) High-throughput salting-out assisted liquid/liquid extraction with acetonitrile for the simultaneous determination of simvastatin and simvastatin acid in human plasma with liquid chromatography. Anal Chim Acta 661(2):167-172. doi:https://doi. org/10.1016/j.aca.2009.12.023

13. Ahmed OS, Ladner Y, Xia J et al (2020) A fully automated on-line saltingout assisted liquid-liquid extraction capillary electrophoresis methodology: application to tyrosine kinase inhibitors in human plasma. Talanta 208:120391. https://doi.org/10.1016/j.talanta.2019.120391

14. Rustum AM (1990) Estimation of Cyclosporin-A in whole blood by simple and rapid reversed-phase HPLC utilizing a salting-out extraction procedure. J Chromatogr Sci 28(11):594-598. doi:https://doi.org/10.1093/ chromsci/28.11.594

15. Hassan J, Bahrani SH (2014) Determination of atorvastatin in human serum by salting out assisted solvent extraction and reversed-phase high-performance liquid chromatography-UV detection $\mathrm{OH}$. Arabian Journal of Chemistry 7(1):87-90. https://doi.org/10.1016/j.arabj c.2013.07.057

16. Song S, Njumbe E, Wu A, Saeger S, De (2013) Development and application of salting-out assisted liquid / liquid extraction for multi-mycotoxin biomarkers analysis in pig urine with high performance liquid chromatography / tandem mass spectrometry. J Chromatogr A 1292:111-120. doi:https://doi.org/10.1016/j.chroma.2012.10.071

17. Tighrine A, Amir Y, Alfaro P et al (2019) Simultaneous extraction and analysis of preservatives and artificial sweeteners in juices by salting out liquid-liquid extraction method prior to ultra-high performance liquid chromatography. Food Chem 277:586-594. doi:https://doi.org/10.1016/j. foodchem.2018.10.107

18. Moreno-González D, Rodríguez-Ramírez R, del Olmo-Iruela M, GarcíaCampaña AM (2017) Validation of a new method based on salting-out assisted liquid-liquid extraction and UHPLC-MS/MS for the determination of betalactam antibiotics in infant dairy products. Talanta 167:493-498. doi:https://doi.org/10.1016/j.talanta.2017.02.045

19. Wang Q, Yin C, Xu L (2013) Optimization of hydrophilic interaction LC by univariate and multivariate methods and its combination with saltingout liquid-liquid extraction for the determination of antihypertensive drugs in the environmental waters. J Sep Sci 36(6):1007-1014. doi:https:// doi.org/10.1002/jssc.201200985

20. Farajzadeh MA, Sheykhizadeh S, Khorram P (2013) Salting-out homogeneous liquid-liquid extraction in narrow-bore tube: extraction and preconcentration of phthalate esters from water. J Sep Sci 36(5):939-946. https://doi.org/10.1002/jssc.201200834

21. Mansour FR, Danielson ND (2017) Solidification of floating organic droplet in dispersive liquid-liquid microextraction as a green analytical tool. Talanta 170:22-35. doi:https://doi.org/10.1016/j.talanta.2017.03.084

22. Mansour FR, Khairy MA (2017) Pharmaceutical and biomedical applications of dispersive liquid-liquid microextraction. J Chromatogr B 1061-1062:382-391. doi:https://doi.org/10.1016/J.JCHROMB.2017.07.055

23. Christopher R, Covington P, Davenport M et al (2008) Pharmacokinetics, pharmacodynamics, and tolerability of single increasing doses of the dipeptidyl peptidase-4 inhibitor alogliptin in healthy male subjects. Clin Ther 30(3):513-527. doi:https://doi.org/10.1016/j.clinthera.2008.03.005

24. Mowaka S, Elkady EF, Elmazar MM, Ayoub BM (2017) Enhanced LC-MS/ MS determination of alogliptin and metformin in plasma: application to a pharmacokinetic study. Microchem J 130:360-365. https://doi. org/10.1016/j.microc.2016.10.002

25. Abdel-Ghany MF, Ayad MF, Tadros MM (2017) Enhanced LC-MS/MS analysis of alogliptin and pioglitazone in human plasma: applied to a preliminary pharmacokinetic study. J Chromatogr B Anal Technol Biomed Life Sci 1058:93-101. https://doi.org/10.1016/j.jchromb.2017.04.043

26. Liu Y, Song L, Yao X et al (2018) A high-performance liquid chromatography-tandem mass spectrometry method for simultaneous determination of imigliptin, its five metabolites and alogliptin in human plasma and urine and its application to a multiple-dose pharmacokinetic study. Biomed Chromatogr 32(11):e4324. doi:https://doi.org/10.1002/bmc.4324

27. Al Bratty M, Alhazmi HA, Javed SA et al (2017) Development and validation of LC-MS / MS method for simultaneous determination of metformin and four gliptins in human plasma. Chromatographia 80(6):891-899. https://doi.org/10.1007/s10337-017-3288-0 
28. Furey A, Moriarty M, Bane V et al (2013) Ion suppression; a critical review on causes, evaluation, prevention and applications. Talanta 115:104-122. https://doi.org/10.1016/j.talanta.2013.03.048

29. ICH (2019) ICH topic M10: bioanalytical method validation. In: International conference on harmonization (February 2019). p. 1-58

30. Wang X, Zhang D, Xu W et al (2010) Pharmacokinetics of lipoyl vildaglip tin, a novel dipeptidyl peptidase IV inhibitor after oral administration in rats. Xenobiotica 40(10):707-712. doi:https://doi.org/10.3109/00498 254.2010 .511683

31. Hyde AM, Zultanski SL, Waldman JH et al (2017) General principles and strategies for salting-out informed by the Hofmeister series. Org Process Res Dev 21(9):1355-1370. https://doi.org/10.1021/acs.oprd.7b00197
32. Collins KD (1997) Charge density-dependent strength. Biophys J 72(1):65-76

33. Attallah MA, Mowaka S, Elkady EF et al (2019) Analysis and bio-analysis of omarigliptin, trelagliptin and alogliptin: applied to biological samples and degradation kinetic study. Microchem J 148:253-261. https://doi. org/10.1016/j.microc.2019.05.010

\section{Publisher's Note}

Springer Nature remains neutral with regard to jurisdictional claims in published maps and institutional affiliations.
Ready to submit your research? Choose BMC and benefit from:

- fast, convenient online submission

- thorough peer review by experienced researchers in your field

- rapid publication on acceptance

- support for research data, including large and complex data types

- gold Open Access which fosters wider collaboration and increased citations

- maximum visibility for your research: over 100M website views per year

At BMC, research is always in progress.

Learn more biomedcentral.com/submissions 